\title{
Un santo de todos y para todos
}

\section{Don Pedro Casaldáliga, Obispo de Sao Félix do Araguaia.}

El jueves 22 de marzo, en el Hospital de la Divina Providencia donde fue asesinado Monseffor Romero, Don Pedro Casaldáliga concedió la siguiente entrevista.

Después de diez años ¿qué significa y qué trascendencia tiene la figura de Monseñor Romero para Latinoamérica?

Cada vez más es él el pastor, el profeta, el mártir de esta parria grande. En su figura se aglutinan todos los mártires de nuestro continente, los mártires que han sido fieles a las reivindicaciones, y hasta a los procesos históricos de nuestros pueblos, y muy concretamente los mártires que han vivido su fe cristiana dando aquel supremo testimonio que decla Jesús, la prueba mayor. Monseffor Romero cada vez más, ya como fruto de su vida de tanto diálogo con todos - diálogo con los ricos, que no lo oyeron; diálogo con los pobres, de los que se hizo oído y voz; diálogo con el Frente, al que corrigió, al que reconoció en sus mejores reivindicaciones- en una especie de santo de los catolicos, de los evangélicos y hasta de los ateos, un santo muy completo, muy universal, como dicen nuestros teólogos de la liberación, un santo político, en el más bello sentido de la palabra, porque su política fue evidentemente esa geopolítica del reino de Dios, pero ubicado en la historia concreta de un pueblo, el pueblo salvadorcino, en esla hora y este lugar, que es Centroamérica, despues del Vaticano II, Medellín y Puebla. En este momento de desaflos, de luchas, de sufrimiento, de muerte, de esperanzas, que es todo nuestro continente. Yo pienso que ahora, cada vez más, se le está haciendo justicia. He ofdo que incluso se inicia el proceso de beatificación. Imagino que tiene sefhal verde por parte de Roma; si no, seguramente la arquidiócesis no lo habria iniciado. Y ahora, a la distancia de los diez affos, y viviendo lo que hemos vivido, su figurz crece. Se nos presenta como una especie de síntesis, ¿no?, de la fe y la historia.

¿Y de qué manera crece en el pueblo?

Sólo basła recorrer las capillitas, los centros comunitarios, hasta las pilas de 
bautismo, de Centroamérica y de América Latina, y va a encontrar a muchos "Romeros". En el interior de capillas desconocidas, de centros comunitarios de las diócesis o prelaturas del Brasil más perdidas, o de otras iglesias de América Latina, usted encuentra a Monseffor Romero. Dudo que hoy haya otro santo más hablado, más conocido. Lo pondríamos aquí en América Latina al lado de San Francisco, al lado de San Anlonio, un santo muy nuestro, que, por otra parte, le ha dado una nueva credibilidad a la Iglesia, al propio evangelio de Jesús, y al Dios de Jesús también.

\section{¿Qué es lo que a usted le llama la atención de todo el trabajo pastoral que realizó?}

En primer lugar su simplicidad de espíritu, su fidelidad a la voz de Dios, y a la voz del pucblo... El salió de una actitud conservadora, en un diálogo al parecer inconsciente, ingenuo, y pasivo con la oligarquía, con la burguesía, y fue capaz de ir creciendo en el compromiso. El pucblo fuc una especie de sacramento suyo. Después él supo mantener la fidelidad como cristiano y como obispo, y al mismo tiempo la libertad de espíritu, aun en medio de la incomprensión de otros hermanos obispos y de algunos sectores de Roma también. $Y$ supo vivir entre muchas balas. En esa balacera con hicliva que era y Lodavía es El Salvador y Centroamérica. Fue simultáneamente un orante, un contemplativo, un profeta denunciador, un pastor muy pastoral, un hombre lúcido, políticamente lúcido, y al mismo tiempo un cristiano sencillo. Oíamos el poema ése. "¿Con qué útulo lo llamamos, doctor de qué?". Pues yo diría doctor del evangelio de los pobres, doctor del evangelio del reino en la historia ya, doctor del evangelio de la liberación, doctor de los procesos de los pueblos encarnándose en el gran proceso de Dios, que es el mismo reino.

\section{¿Qué significa para usted la muerte de nuestro obispo mártir ante el altar?}

Yo creo que Dios quiso sellar la autenticidad de su vida cristiana, su capacidad de oblación, a lo largo de los últimos años de su vida, dándole no sólo la gracia del martirio, sino la gracia de un martirio tan ubicado encima del propio martirio pascual de Jesús. Para mí lue una especie de canonización del Padre. Ese altar del Hospitalito, un hospital para personas que tienen cáncer donde vivía Romero, y en la capilla, donde lo asesinaron cuando estaba celebrando misa, es como una gran reliquia. Antes poniamos pedacitos de reliquias en el ara del altar, y esta capilla para mí es una especie de gran santuario de toda América Latina. Para nosotros, los obispos, muy particularmente, hoy, aquí, en este continente, en esta hora crucial, es una luz de desafio, un cobro, quizás un remordimiento. También un estímulo y una esperanza. El deća que con este pueblo es fácil ser obispo. Yo diría que para nosotros, en cualquier pueblo de América Latina, después de obispos como Romero, ya quizás no nos resulta tan difícil ser obispos. Por Romero sí queremos ser fieles y aprovechar el ejemplo de su testimonio. 
¿Cual es su opinión en particular sobre las posibilidades de alcanzar la paz en El Salvador?

Humanamente hablando, no parece asl tan próxima. Pero el pueblo tiene su camino y Dios hace sus misericordiosos milagros. Yo pienso que en medio de ese desconcierto y de esas decepciones, en esa pertinacia de ejércitos prepotentes y crueles del imperio, controlándonos, invadiéndonos, caminamos. Yo tengo una esperanza de que estamos empezando la última década del imperio, y estamos empezando la década de otra revolución, que sería la revolución de la democracia. Pero no de la democracia que nos imponen, no de la democracia liberal burguesa, sino de la democracia popular participativa, de la democracia econónica, social, cultural, lécnica, de la democracia latinoamericana. Estamos cansados ya de imperios de cualquier signo, estamos cansados de dictaduras de cualquier signo, y estamos cansados tambiên de democracias burguesas. Queremos juntar una socialización de la economfa con una democracia politica, y un pluralismo ideológico, religioso. Nosotros, cristianos, a partir de nuestra fe, viviendo con gozo, con compromiso, con humildad, con libertad, nuestra fe cristiana. Bromeando un poco dentro del clima que vivimos de las noticias tan recientes, universales, el propio papa Juan Pablo II les decía recientemente a un grupo de obispos brasilefios que estuvieron en la visila ad limina, que ahora hace falta la perestroika del capitalismo. Nosotros queremos una perestroika total, y con carifio de casa, porque Iglesia somos. También debemos ir procurando la perestroika de la propia Iglesia, y sobre todo el glasnot de la Iglesia. Jesús nos dice que seamos trasparentes, sencillos como las palomas. Yo pienso que nosotros, todos - papa, obispos, sacerdotes, religiosos, laicos- debernos ser libres, abiertos, trasparentes. Al fin y al cabo, nuesta ley es el evangelio, sabiendo por otra parte que debemos seguir siendo astutos, como las serpientes, porque en este mundo estamos, y vivimos coyunturas y estructuras políticas, económicas e históricas. Yo tengo mucha esperanza. La muerte de Romero, en última instancia, no deja de ser una muerte pascual. Y la pacua hacia la que vamos -estamos en cuaresma - es muerte, no hay duda, y es desierto, es ayuno de muchas cosas. Nuestro pueblo ayuna constantemente en el hambre, en la privación de todo, hasta de la identidad. Pero vamos hacia la resurrección.

¿Dirlas que eres una persona distinla por haber conocido -en sus palabras y actuación-a Monseñor Romero? ¿Cómo?

Me confirmó en la opción por los pobres. Al mismo tiempo me confirmó en la voluntad de ser fiel a la oración, a la contemplación. Me confirmó también en esta libertad de espíritu dentro de la conflictividad de los procesos de nuestros pueblos, aun sintiéndonos tal vez incomprendidos por hermanos obispos y a veces incluso por algún sector del Vaticano. Y me confirmó también en la pasión que ya inicialmente sentfa por esta Centrœamérica, que es un poco eje y 
corazón de todo el continente. Y Romero me da, dirlamos, la satisfacción -que creo que es evangélica - de scr obispo en este tiempo, en este lugar. Vale la pena ser obispo, habiendo obispos como Monseffor Romero.

Monseñor Romero dijo que, en medio de las dificultades de sus años como arzobispo, lo que le dio ánimo para seguir adelante fue el pueblo. ¿HIas experimentado algo parecido?

Evidentemente. Si no fuera por el pueblo, primero por el sufrimiento del pueblo, segundo por la esperanza del pueblo, tercero por el carifio del pucblo, ni valía la pena ser obispo. Podria $-y$ vale la pena, claro- ser contemplativo encerrado en un convento, y creo en la contemplación de los contemplativos. Pero ser obispo sin pueblo, o ser obispo distante del pueblo, o ser obispo negándose al clamor y al proceso del pueblo, sería negar el propio ministerio. Asi como no hay Iglesia sin obispo, tampoco hay obispo sin Iglesia. Y, evidentemente, la Iglesia acontece en este pueblo concreto -indígenas, campesinos, obreros-, no tienen tierra, son perseguidos, luchan por su liberación, viven en su fe en una religiosidad popular. Nosotros tenemos como dos grandes sacramentos: el propio evangelio encarnado en Cristo, y la historia del reino de Dios, que también acontece en la historia, encamado en nuestro pueblo, en el pueblo concreto en medio del cual vivimos y del cual somos pastores.

Pedro Casaldáliga y los mártires salvadoreños

Clamor de aniversario

Romero, Romero hermano, van diez afios de tu muerte. ¿Tu muerte habrá sido en vano?

Tu pueblo sigue en la suerte de una vida prohibida y sigue de muerte herida la paz en EI Salvador y es un último clamor loda la sangre verida con tu sangre de pastor.

Capilla del Hospitalito, San Salvador, 22 de marzo de 1990. 


\section{La UCA y el pueblo herido}

Ya sois la verdad en cruz y la ciencia en profecía y es total la companfa. companteros de Jesús. El juramento cumplido, la UCA y el pueblo herido dictan la misma lección desde las cátedras fosas y Obdulio cuida las rosas de nuestra liberación.

Capilla de la UCA, San Salvador, 23 de marzo de 1990. 